\title{
Parents' Involvement in the Education of their Children with Autism: Related Research and its Results
}

\author{
https://doi.org/10.3991/ijet.v15i14.12509 \\ Irene Chaidi ${ }^{(凶)}$, Athanasios Drigas \\ Net Media Lab-Mind \& Brain R\&D, N.C.S.R. 'Demokritos', Athens, Greece \\ Institute of Informatics and Telecommunications, N.C.S.R. 'Demokritos', Athens, Greece \\ irhaidiegmail.com
}

\begin{abstract}
Parents' active participation in the diagnostic and therapeutic process of children with developmental disorders is considered by experts to be an important factor in the long-term struggle to educate people with autism. According to relevant bibliographical references, the benefits of parental education have been proven for decades. Researchers [1], [2] underline the positive outcomes of parent behavior training programs for children with developmental disabilities.

Surveys conducted to date show that results show parents can implement the strategies they have recently learned and are generally very pleased with parent's education programs. However, findings related to children's communication and socioemotional skills, parent-child interactions were unclear [3].
\end{abstract}

Keywords - Autism, parents, parent education Introduction

\section{Introduction}

In recent years, the need for active parental involvement in the diagnostic and therapeutic process of children with different developmental disorders has been emphasized as it is now considered an important factor in the long-term outcome of major difficulties. Emphasis is also placed on the importance of supporting and educating parents to make use of their potential to promote the quality of life of the child and the family [4].

The present work is a bibliographic review of research related to the education of parents of children with diffuse developmental disorders and which focuses on the active involvement of parents in the process of educating their children.

\section{$2 \quad$ Autistic Spectrum Disorder (ASD)}

Autistic Spectrum Disorder is a severe, widespread disturbance of a person's development that accompanies the person throughout his or her life, affecting one's perception, thinking and behavior and is characterized by a) significant difficulties in 
developing social and communication skills and mutual interactions. the person with those around him, and (b) limited and repeated stereotypical interests and behaviors [5].

ASD is diagnosed by comparing one's behaviors with the symptoms described in the official Diagnostic and Statistical Manual of the American Psychiatric Association and ICD-10 (International Classification of Diseases). of the World Health Organization (WHO).

Both the current diagnostic criteria and the descriptions of modern Autism researchers follow Wing's "Trinity of Social Interaction Disorders" [6]: a) Social Relationship Disorders - Incomplete Social Interaction - Interactivity, Emotional Deficits, Communication disruption - incomplete communication and c) Disruption of social understanding and imagination - lack of social understanding and imagination [7]. These three categories, with the revised version 5 of the DSM (DSMV), were replaced by 2 groups: a) social communication and b) stereotyped, repetitive behaviors, activities, and interests.

It should be emphasized that children with ASD are highly heterogeneous about concerning social disorder. Other children have a lack of motivation for interaction, which in some cases avoids interaction, that is, they avoid touch and eye contact, while others actively seek interaction but either lack empathy or interact interactively. People with ASD also have a disadvantage in their emotional organization, resulting in the difficulty of communicating with those around them, with the consequences of socialization difficulties and their family [8].

\section{The Role of Parents in Autism}

In recent years, widespread developmental disorders have attracted the interest of both parents and health and education professionals and constitute areas of great research, clinical and social interest [9]. Research interest also focuses on parents and the family in the field of autism as well as on the effectiveness of the early intervention and parent education. It is generally accepted that the family is a key factor in physical and mental development and that the child-family relationship is two-way as parents influence the child, which in turn influences the parents [10]. Parents are also "experts" in their child, they know it better than anyone and can provide any information that will be valuable in their child's education and therapeutic approach. The views held over many years about parents' responsibility for their behavior and the upbringing of their child in the emergence of autism today are unacceptable. Today, the emergence of autism is considered to be the result of organic causes and the contribution of parents in coping with the difficulties of the crucial disorder [11]. Parents are considered co-therapists [12], can provide necessary information about the child's daily life, development and course, participate actively in treatment, support the therapeutic-educational process, and play a leading role in claiming the rights of their child, 115 in educating and supporting other parents in coping with the difficulties and negative emotions resulting from having a person with autism. However, one factor that can have a positive impact on the role of parents in making use of their potential 
is quality cooperation with specialized health and education professionals specializing in the field to ensure the development and quality of life of their child. [4]. According to a statement from the Department of Education and Science in Great Britain [13], "effectively addressing the needs of people with developmental disorders depends on the full involvement of parents. The relationship between them and health and education professionals is crucial to the child's development. Parents need information and clear guidance to support the efforts of professionals, while it is impossible for professionals to meet the needs without valuable knowledge of the parents about their child

\section{The Role of Parents in the Educational Program}

The role of parents in the therapeutic program is considered as cited as therapeutic because their involvement is considered as important as that of the special educators in achieving the best possible results and is deemed necessary and consistently rather than occasional.

The involvement of parents in the treatment program can play a decisive role in the outcome of treatment. The systematic training of parents helps to regain their lost confidence and reduce their stress to meet their parental role requirements. According to researchers [14], [15] and [16] the reasons why parental involvement is necessary are: a) the multiple needs of children with ADHD and their chronic nature, b) the difficulties that show: sleep disturbances, eating disorders, anger bursts, etc., c) difficulty adjusting to new environments, d) behavioral problems, e) difficulty in generalization and f) difficulty in retaining acquired knowledge, skills, etc, without systematic and continuing education. Parenting experience and knowledge may seem to be the major contributors to the successful education of children with autism, and the absence of parents from the design and implementation of any program implemented can be a factor in failure. When parents and teachers look for ways to help the child, each with respect for each other's experience, they can develop new educational approaches that might not have been developed without this type of work [17],[18]. The life of a child with autism continues at home and with his or her family, so educational programs implemented to include at all stages the parents of children with autism can only be achieved with bona fide and consistent cooperation. teachers and parents [19].

\section{The Education of Parents}

The education of their parents enables them to participate in their child's treatment program to enhance their learning progress and improve their behavior. The parenting tools of children with autism and the techniques used to contribute to better parenting, with the primary and primary purpose of their education being to develop a relationship of trust and appreciation between the educator-therapist and the parents. The program also builds on the individual goals of each child that are prioritized based on their needs and abilities. 


\section{$6 \quad$ Method}

The present work reports recent research on the usefulness of parent education as well as school education for children with an autism spectrum disorder to participate in the education of their children in collaboration with specialists.

One of the interventions investigated was inclusive education, that is, co-education of normal and autistic children in the classroom. Researchers [20] conducted action research. The intervention program was carried out in the 1st-3rd nth grades, 4 urban public primary schools in Rethymnon (Crete), at different times, as different intervention-research projects (4 teams in total) were used, between the beginning of 2008 and the end. 2011. 94 students (6-8 years) were in these classrooms at the time of program implementation. Many of them (20-25) presented various difficulties that varied in form, duration, intensity or severity and source. The results showed that teachers and parents saw this intervention model very positively and gained significant knowledge of practices related to their role.

Another intervention that was studied was early intensive intervention. Researchers [21] reviewed 1,500 articles referring to studies of parent education of children aged 1-6 years. All referrals generated through the search strategy were transferred to an EndNote Reference Program. The initial sorting of titles and summaries from the search identified potential studies for inclusion. Studies that differed greatly from the inclusion criteria were excluded, while those studies that appeared to be appropriate were kept, i.e., those that appeared to be for intervention in children with an autism spectrum disorder, and there was some reference to the role of parents. Critics evaluated independently and selected studies to include from the remaining studies. Two important results were found to favor parent training in one study: children's language and mother's autism. Intensive intervention (involving parents) concluded that there is good evidence for positive change in both parental perceptions and the implementation of strategies to improve the behavior of children with autism. Also, other researchers [22] conducted questionnaires and interviews with 15 families who used this intervention. When parents were asked to identify the aspects of intervention they valued most, communication assistance was a topic that was strongly reported (out of ten families). Some parents particularly emphasized how their child's developing language and communication skills helped them become more integrated into the behavior of families as well as the child.

Researchers [3] conducted a review of studies regarding the education of parents of children with autism spectrum disorders. Systematic searches were conducted to retrieve studies in which at least one parent was trained to apply specific techniques to their young children (0-36 months) who have been diagnosed with autism spectrum, and finally, 15 studies, involving 484 children (mean age), were analyzed. 23.26 months). The results show that parents were able to apply the newly learned strategies and were generally very satisfied with the parent training programs. However, the findings on children's communication and socio-emotional skills, parent-child interactions, and parental well-being were ineffective.

Other researchers [23] also reviewed studies that specifically analyzed 17 studies from 6 countries (USA, UK, Australia, Canada, Thailand, and China), including 919 
children with autism. These studies were related to 117 interventions to enhance the style of parent interaction and thus facilitate children's communication. The review finds some evidence for the effectiveness of parent-mediated interventions, more specifically on central indicators in parent-child interaction, but also on more extreme indicators of children's linguistic understanding and reduction in the severity of autism. Evidence of whether such interventions can reduce parental stress is ineffective.

In an intervention study of correspondent teaching, researchers [24] applied the intervention to a randomized control group of 19 preschool children from Turkey with difficulties and their mothers, while there was also a control group. Compared to the control group, mothers who participated in responsive teaching had significantly greater increases in responsiveness and influence, while their children made greater changes in their commitment or central behavior. There were also significant differences in children's developmental outcomes. Children in the responsive teaching group improved their developmental outcomes by an average of $42 \%$ versus $7 \%$ for the children in the control group.

Also, another study [25] experimentally applied 21 parenting interventions to parents of preschool children with developmental disabilities. The results show that this parenting intervention was superior to the usual care for young children with developmental delays or special needs in limiting negative parent-child interactions and children's behavior problems. Participants in the experimental group showed high satisfaction with the treatment. Besides, another researcher [26] studied the impact of parenting programs for children with autism spectrum disorders on 79 parents who represented 58 children using questionnaires. The questionnaires were used to evaluate seven consecutive 11-session programs, and the results showed that the course produced positive outcomes in terms of parent satisfaction, parent learning, and perceived changes in children's behavior.

Other popular interventions are behavioral. In this area, researchers [27] applied two interventions, 'parenting and counseling' and 'parenting education and behavior management', to two groups of 35 individuals and had another group of 35 individuals implemented no intervention. Parent education and behavior management led to a significant improvement in adaptive behavior and autism symptoms at 6 months of intervention for children with greater delays in adaptive behavior. Parent education and behavior management were superior to parent education and counseling. Another study [28] reviewed 18 studies of positive behavior interventions, and the findings revealed that researchers reported general information about family partnerships. Finally, several years ago other researchers [2] had studied the effect of parenting behavioral training programs on 17 mothers and 2 fathers. Judges who were asked to evaluate the positive impact of the parents worked in one-on-one training sessions with their children. The parents applied either a highly structured, discriminatory test procedure or a more naturalistic centralized education process. The results showed that parents who applied the central training procedure were found to have more positive effects than those parents who applied the discriminatory test procedure.

The DIR / Floortime model is another intervention model that has been studied for its effects. Specifically, researchers [29] applied the model to 68 children and made videotape assessments before and after application 118 using the functional emotional 
rating scale. They found that $45.5 \%$ of children had good to very good improvement in functional development. The same model was also investigated by other researchers [30] who performed functional effective development and symptom severity in 32 24-72- month- old children. It was found that after home-based DIR / Floortime intervention at an average of 15.2 hours /week for three months, the intervention group had significantly higher gains in all three measures adopted in the study: Functional Emotional Rating Scale, Autism Rating Scale age and functional emotional questionnaires.

Also, researchers [31] applied the natural language example to 3 parents of children with autism. The data collected through a questionnaire on parental involvement indicated a great deal about the use of children's language and play. There was a shift from mimicry at the beginning of the intervention to spontaneous language at the end of intervention for all three children but also clear improvements in play for two out of three children. In response to a social power questionnaire, parents indicated that they found the study useful and the procedures simple and that they would continue to use intervention at home after the study was completed.

Finally, other researchers [32] studied the effects of applying early triad interaction on 1 Swedish family, making quantitative and qualitative observations. Compared to other families without autistic children, the divergence occurred in the early triadic synchronization, particularly when the girl was nine months old. At three months, the girl participated in more sequences than the other children, at nine months, she paid more attention to objects while at 18 months, she had less eye contact with her parents and less shared focus, and at 48 months her language skills were poorly developed. The mother focused on repeated observation-observations on the infant's age while the father referred to deviations in the attention of the child and the negative developmental vocal skills of the child at 18 months.

\section{$7 \quad$ Conclusions - Perspectives}

Recent estimates of the prevalence of autism spectrum disorder (ASD) suggest that at least one in 200 children is affected. This group of children and families has significant service needs. Parents' involvement in implementing intervention strategies designed to help their autistic children has long been accepted as helpful. The potential benefits are increased skills and reduced stress for both parents and children [21].

The results of the literature review have shown that there are positive effects on parents' training in methods and strategic interventions, so that they can continue to participate in the education of their children successfully in intervention, especially in young children with ASD. However, the need to improve research in this area is emphasized as the need for researchers to understand and document the characteristics of effective intervention in the families of children with ASD has been recognized. Despite the positive findings in research, scientists believe that there is a lack of information about the specific strategies used to teach parents, the models used in educational programs, what kind of teaching or protocols are used, and how they are used. , if parental education is associated with intervention in the child, how do parenting 
programs evaluate which programs and with what outcomes do they relate to education the parent [33]. Researchers [1] report that according to the literature review the components studied in the studies are as follows: (a) the purpose of the parent education or the target skills of the parent education program; whether or not the parent was educated with the child present, (c) the ages of the target children, (d) the type of parent education program, (e) the structure of the program materials used, (f) the frequency of the program, (g) the duration of the program; (h) parent effects; (i) child outcomes $(\mathrm{j})$ the design research used to evaluate the parent education program, and (k) whether or not the data was collected for the validity of the implementation of the parent education program.

They detail that the purpose of parent education is to learn targeted skills that use techniques to improve behavior or communication. In most studies it is evident that mothers 'participation in education is high while fathers' is low. Also, several studies indicate that it was present in maternal education and the child, while others do not specify its presence. Another component of the surveys was the ages of children, summarized in four categories, based on chronological-developmental age groups: younger than 3 years, 3-5 years, 6-13 years, and more (over a range of ages 13 years). Half of the parent education programs are aimed at parents of children between the ages of 3 and 5, 17\% for parents of children under 3, 10\% for parents of children 6 to 13 , and $23 \%$ for parents with children over 13 years old. The third component relates to the form of delivery used and which are 3: a) one to one, b) a group in combination with one to one c) not named. One aspect of the studies that is mentioned is the use of the types of program materials, curriculum, or textbook. As noted in the studies, only $43 \%$ used some kind of training manual or provided a parenting manual that provided process information. It is also noted that the duration and frequency of parent training programs could not be classified as a fixed "total duration and frequency in hours" was not presented. The effectiveness of educational programs is achieved by collecting data in three main ways: (a) observational behavior; (b) standardized assessment; and (c) maternal exposure research and are categorized as: a) skills improvement, b) stress reduction. (c) reducing challenges; (d) increased knowledge either of their child's behavioral or disability strategies in general; and (e) they are not named. Finally, there is the design research used to evaluate the parent education program where the majority of studies reported using a single-page case study to evaluate parent education programs.

\section{$8 \quad$ Prospects}

According to researchers [34] future studies of early intervention for children with ASD should be large enough for safe conclusions in statistical analysis, including a long-term follow-up evaluation, at least one year schedule, and include a complete evaluation. Studies should use widely recognized standardized tools to evaluate the outcome in terms of children's social and communication behavior, skills, and secondary behavioral problems, to allow others to assess the level of clinical relevance. Investigations should be designed in such a way as to have an appropriate degree of 
equilibrium, to be able to choose between two alternative 120 interventions with firm beliefs about their relative efficacy by clinicians or participants. Balance is a requirement for RCT methodology, but it is particularly difficult to achieve research in young children with ASD. The context in which future parents' intervention is to be evaluated should be carefully considered as their education is not just a component of early intervention for children with ASD because parents need not only initial training in new skills but continuous support for their children. of their children. So in the future, evaluations should consider what elements of intervention can be combined in the most rational way to provide effective family care and support packages. After all, autism is acomplex and multifaceted disorder with a range of severity, with "demands" from parents, and families have a different ability to respond to additional pressures such as actively supporting their children's educational program.

\section{References}

[1] Schultz, T., Schmidt, C., and Stichter, J. (2011). A Review of Parent Education Programs for Parents of

[2] Children with Autism Spectrum Disorders. Focus on Autism and Other Developmental Disabilities, 26 (2), 96-104.

[3] SCHREIBMAN, L., KANEKO, W., KOEOEL, R. (1991). Positive Affect of Parents of Autistic Children: A Comparison of Across Two Teaching Techniques. BEHAVIOR THERAPY, 22, 479-490. https://doi.org/10.1016/s0005-7894(05)80340-5

[4] Beaudion, A., Sebire, G., Conture, M., (2014). Review Article: Parent Training Inteventions for Toddlers with Autism Spectrum Disorder. Autism Research and Treatment , 2014 , 15. https://doi.org/10.1155/2014/839890

[5] Papageorgiou, B. (2008). TO THE PARENTS ..., TO THE PARENTS ...,. Retrieved 2 5, 2018, from http://repository.edulll.gr/edull1/retrieve/1837/318.pdf

[6] Association, AP (1994). Diagnostic and Statistical Manual of Mental Disorders, 5th edn (DSM-V). Washington DC: American Phychiatric Association.

[7] Wing, L. (1998). Autism spectrum disorders. A guide to diagnosis. The autobiographies of autistic people. Athens: Greek Society for the Protection of Autistic Individuals.

[8] Happe, F. (1998). Autism. Athens.: Gutenberg.

[9] Chaidi, E. (2016). Autism, expression and emotion comprehension: a book review. 2nd Panhellenic Conference with International Participation in the Promotion of Educational Innovation (EEEPEK), Volume I, pp . 346-354. Larissa.

[10] Shields, J. (2001). The NAS Early Bird Program. partnership with Parents. Autism, 5 (1), 49-56. https://doi.org/10.1177/1362361301005001005

[11] Schiamberg, L. (1985). Human Development. New York: Macmillan.

[12] Christier, P. and Hall, B. ((1993).). Parents as Partners: Autism. Birmingham: University of Birmingham.

[13] Rutter, M. and Schopler, E. (1987). Autism and pervasive developmental disorders: Concepts and diagnostic issues. In MT In Rutter, Assessment and Classification in Child and Adolescent Psychiatry. New York: Guilford Press. https://doi.org/10.1007/bf01495054

[14] Science, D. o. (1978). Special Education Needs: Report of the Inquiry Committee into the Education of Handicapped Children and Young People. London: HMSO. 
[15] Kypriotakis, A. (1997). School integration: General requirements and the specific role of parents. In E. Tafa, Co-education of children with and without learning and behavioral problems. (pp. 379-397). Athens: Greek Letters.

[16] Kypriotakis, A. (1995). Autism and their treatment. Heraklion: Author's version.

[17] McClannahan, LE, Krantz, PJ, \& McGee, G. (1982). Parents as therapists for autistic children: A model for effective parent training. Analysis and Intervention in Developmental Disabilities, 2, 223-252. https://doi.org/10.1016/0270-4684(82)90020-9

[18] Christie, P. (1985). The home supports the needs of families of autistic children. Seminar presentation.

[19] Newson, E. (1985). Supporting parents as members of the autistic child team. Conference presentation.

[20] INSTITUTO, PC (2004). Cartography - Special Education Curricula, Curricula for Students with Autism.

[21] Kourkoutas, El., Eleftherakis, Th., Vitalaki, El., \& Hart, An., (2014). Family-SchoolProfessionals Partnerships: An Action Research Program to Enhance the Social, Emotional, and Academic Resilience of Children at Risk. Journal of Education and Learning; (2015), 4 (3). https://doi.org/10.5539/jel.v4n3p112

[22] Diggle, T., Randle, VRL \& McConachie, H. (2003). Parent implemented early intervention for young children with autism spectrum disorder. (1).

[23] Webster, A., Feiler, A., Webster, V., Lovell, C. (2004). Parental Perspectives on Early Intensive Intervention for Children Diagnosed with Autistic Spectrum Disorder. Journal of Early Childhood Research, 2:25. https://doi.org/10.1177/1476718x0421002

[24] Oono IP, Honey EJ, McConachie H. (. (2013). Parent-mediated early intervention for young children with autism spectrum disorders (ASD). This is a reprint of a Cochrane review, prepared and maintained by The Cochrane Collaboration (4). https://doi.org/10.10 02/ebch.1954

[25] Karaaslan, O., Diken, Ib., Mahoney, G., (2011). A Randomized Control Study of Responsive Teaching with Young Turkish Children and Their Mothers. (HI 2011, Ed.) Topics in Early Childhood Special Education, 33 (1), 18-27. https://doi.org/10.1177 $\underline{10271121411429749}$

[26] McIntyre, L. (2009). Parent Training for Young Children with Developmental Disabilities: A Randomized Controlled Trial. PMC Journals, 113 (5), 356-368.

[27] Pillay, M., Alderson-Day, B., Wright, B., Williams, Ch., And Urwin, Br, (2011). Autism Spectrum Conditions - ASCEND: An evaluation of intervention support groups for parents. Clinical Child Psychology and Psychiatry ,Psychiatry,0. https://doi.org/10.1177/1359 $\underline{104509340945}$

[28] Tonge, B., Brereton, A., Kiomall, M., Mackinnon, A., Rinehart, N. (2012). A randomized controlled comparison trial of 'preschoolers with autism': A parent education and intervention training skills for young children with autistic disorder. Autism published online 17 September 2012. https://doi.org/10.1177/1362361312458186

[29] McLaughlin, T., Denney, M., Snyder, P., and Welsh, J.,. (2012). Behavior Support Interventions Implemented by Families of Young Children: Contextual Fit Examination. Journal of Positive Behavior Interventions, 14 (2), 87- 97. https://doi.org/10.1177/109830071 $\underline{1411305}$

[30] SOLOMON, R., NECHELES, J., FERCH, C., B RUCKMAN, D. (2007). Pilot study of a parent training program for young children with autism The PLAY Project Home Consultation autism program. SAGE Publications and The National Autistic Society, 11 (3), 205224. https://doi.org/10.1177/1362361307076842 
[31] PAJAREYA., K., NOPMANEEJUMRUSLERS., K., (2011). A pilot randomized controlled trial of DIR / Floortime TM parent training intervention for pre-school children with autism spectrum disorders. The National Autistic Society, 15 (5), 563-577. https://doi.org/ $10.1177 / 1362361310386502$

[32] Gillett, J., LeBlanc, L., (2007). Parent-implemented natural language paradigm to increase language and play in children with autism. Research in Autism Spectrum Disorders (1), 247-255. https://doi.org/10.1016/j.rasd.2006.09.003

[33] Hedenbro, M., Tjus, T. (2007). A case study of parent-child interactions of a child with autistic spectrum disorder (3-48 months) and comparison with typically-developing peers . Child Language Teaching and Therapy, 23 (2), 201-222 2007. https://doi.org/10.1177/026 $\underline{5659007076294}$

[34] Lord, C., Wagner, A., Rogers, S., Szatmari, P., Aman, M., Charman, T., Yoder, P. (2005). Challenges in evaluating psychosocial interventions for autistic spectrum disorders. Journal of Autism and Developmental Disorders, 35, 695-708. https://doi.org/10.1007/s108 $\underline{03-005-0017-6}$

[35] McConachie, H., Diggle., T., (2005). (nd). Parent implemented early intervention for young children with autism spectrum disorder: a systematic review. Journal of Evaluation in Clinical Practice. https://doi.org/10.1111/j.1365-2753.2006.00674.x

\section{Authors}

Irene Chaidi is currently working as a special education teacher in Athens, Greece. She is a Ph.D. Candidate in N.C.S.R. 'Demokritos', Institute of Informatics and Telecommunications, Net Media Lab, and Mind-Brain R \& D, Agia Paraskevi, 153 10, Athens, Greece (e-mail: irhaidi@gmail.com).

Athanasios Drigas is with N.C.S.R. 'Demokritos', Institute of Informatics and Telecommunications, Net Media Lab, and Mind-Brain R \& D, Agia Paraskevi, 153 10, Athens, Greece (e-mail: dr@iit.demokritos.gr).

Article submitted 2019-11-26. Resubmitted 2020-04-21. Final acceptance 2020-04-21. Final version published as submitted by the authors. 